\title{
Supressão de Plantas daninhas e Produção de Milho-Verde Orgânico em Sistema de Plantio Direto ${ }^{1}$
}

\author{
Weed Suppression and Organic Green Corn Production in No Tillage System \\ QUEIROZ, L.R. ${ }^{2}$, GALVÃO, J.C.C. ${ }^{3}$, CRUZ, J.C. ${ }^{4}$, OLIVEIRA, M.F.. e TARDIN, F.D. ${ }^{4}$
}

\begin{abstract}
RESUMO - O sombreamento do solo com cobertura morta proporciona redução na germinação das sementes e diminuição da população de plantas daninhas, possibilitando às plantas da cultura de interesse se desenvolverem sob efeito de menor competição inicial. Dessa forma, objetivou-se neste trabalho investigar o efeito do cultivo de leguminosas na evolução da comunidade de plantas daninhas na cultura do milho-verde cultivado em sucessão, num sistema orgânico. O ensaio foi realizado em delineamento em blocos ao acaso, com parcelas subdivididas e quatro repetições. Inicialmente, houve o plantio das leguminosas: feijão-deporco (Canavalia ensiformes), guandu (Cajanus cajan), mucuna-preta (Mucuna aterrinum), mucunaanã (Mucuna deeringiana) e crotalária (Crotalaria juncea); foi mantida uma testemunha sem cultivo em pousio. Anteriormente ao cultivo do milho, foi avaliada a produção de matéria seca de cada espécie de leguminosa. Em seguida, após a roçada das leguminosas foi semeado sobre a palhada o milho, cultivar HTMV 02. A amostragem das plantas daninhas foi realizada aos 15 e 30 dias após a emergência do milho, lançando-se de forma aleatória sobre cada parcela um quadro de 50 x $50 \mathrm{~cm}$. As plantas daninhas dentro do quadro foram identificadas, pesadas e contadas por espécie, sendo posteriormente colocadas em estufa a $65^{\circ} \mathrm{C}$, por 72 horas, para determinação da matéria seca. As palhadas da mucuna-preta e da crotalária proporcionaram maior redução de matéria seca e população das plantas daninhas. A maior produtividade de espigas comerciais de milho-verde foi obtida na área de palhada de mucunapreta e crotalária.
\end{abstract}

Palavras-chave: cobertura verde, cobertura morta, cobertura de solo, manejo cultural, Zea mays.

\begin{abstract}
Soil shading using mulch reduces weed seed germination and, consequently, weed population, allowing the plant of interest to develop free of the initial competition. Thus, the aim of this paper was to evaluate the effect of leguminous plant cultivation on the evolution of a weed community on green corn cultivated in succession under an organic system. The trial was conducted with leguminous plants during the 2007/2008 season, at the Embrapa Corn and Sorghum Field Center in Sete Lagoas-MG. The experiment was arranged in a completely randomized block design with split-plots and four replications, with five species of leguminous plants being evaluated: jack bean (Canavalia ensiformes), pigeonpea (Cajanus cajan), mucuna-black (Mucuna aterrinum), mucuna dwarf (Mucuna deeringiana) and Crotalaria juncea, plus a control, spontaneous vegetation of the area. On February/2008, the leguminous plants were cut close to soil and corn was planted overthis mulch on March/06/2009. Weed samplings were collected at 15 and 30 days after corn emergence, which was randomly thrown on each plot framework, measuring $50 \times 50 \mathrm{~cm}$.. The weed plants within the framework were identified, weighed and counted. The results obtained showed that Mucuna aterrinum and Crotalaria juncea cover provided further weed biomass reduction during the two seasons evaluated. Higher commercial green corn ear yield was obtained when soil cover using Mucuna aterrinum and Crotalaria juncea straw was adopted.
\end{abstract}

Keywords: green cover, mulch, soil cover crops, cultural management, Zea mays.

Recebido para publicação em 3.7.2009 e na forma revisada em 15.6.2010

2 Engo-Agr ${ }^{0}$, Dr., pós-doutorando, Departamento de Fitotecnia, Universidade Federal de Viçosa - DFT/UFV, 36570-000 ViçosaMG, <lrodqueiroz@yahoo.com.br>; ${ }^{3}$ Eng$^{-}-$Agr $^{\circ}$, D.Sc., Professor Associado, DFT/UFV, <jgalvao@ufv.br>; ${ }^{4}$ Engo-Agr ${ }^{\circ}$, Dr., Pesquisador, Embrapa Milho e Sorgo, Caixa Postal 151, 35701-970 Sete Lagoas-MG. 


\section{INTRODUÇÃO}

A cobertura morta contribui para o sombreamento do solo, inibindo a germinação das sementes e infestação de algumas plantas daninhas, possibilitando assim que a cultura principal inicie o seu desenvolvimento com menor competição inicial. Esse efeito é dependente do tipo de resíduo da cobertura, da sua distribuição na superfície do solo e da quantidade de material disponivel (Almeida, 1988)

A importância da utilização de métodos alternativos no controle de plantas daninhas na cultura do milho está fundamentada no grande número de pequenos produtores sem tecnificação e na composição do custo total de produção no cultivo orgânico, representando cerca de $18 \%$ do custo para o manejo de plantas daninhas (Cruz et al., 2006)

O sistema de produção orgânica de milho no plantio direto tem como principal desafio o manejo das plantas daninhas, principalmente no período da transição da lavoura convencional para a orgânica (Fontanetti et al., 2006). Nesse sistema, o método químico é substituído, na maior parte das vezes, por métodos mecânicos e/ou culturais, como a utilização de plantas de cobertura do solo. Essas plantas devem apresentar crescimento inicial rápido e grande produção de matéria seca, tendo a capacidade de sombrear e inibir o desenvolvimento das plantas daninhas. Durante o ciclo da cultura pode-se utilizar, ainda, a roçada das plantas daninhas, aliada a outras práticas culturais de manejo (Darolt \& Skora Neto, 2002). No entanto, a eficiência dessa roçada depende, em grande parte, das espécies de plantas daninhas, da frequência do corte e do estádio de desenvolvimento das plantas.

A utilização exclusiva da roçada, no sistema de plantio direto orgânico, tem levado ao estabelecimento de espécies de plantas daninhas que apresentam rebrota, dificultando o seu manejo na cultura do milho-verde (Vaz de Melo et al., 2007). Nota-se ainda maior produção de matéria seca total de plantas daninhas no sistema de plantio direto orgânico, em comparação ao sistema de plantio direto tradicional. Isso se deve principalmente à alta capacidade de rebrota de algumas espécies de plantas daninhas, como, por exemplo, Bidens pilosa. Entretanto, a interferência de
Bidens pilosa sobre o desenvolvimento das plantas de milho é minimizada quando se realiza a capina no estádio de quatro folhas, sendo a roçada não indicada como método de controle dessa espécie (Chiovato et al., 2007).

Novas alternativas, visando minimizar os impactos ambientais, têm sido pesquisadas, entre as quais a aplicação dos efeitos alelopáticos de plantas cultivadas sobre as plantas daninhas, suprimindo seu desenvolvimento e reduzindo a infestação. Considera-se importante o estudo dos efeitos alelopáticos de plantas de adubação verde, que, além de promoverem melhoria para o solo, poderiam atuar como um método natural de controle de plantas daninhas em cultivos sucedâneos, possibilitando, assim, redução no uso de herbicidas. Estudos envolvendo minimização de impacto ambiental no desenvolvimento de programas de manejo de plantas daninhas tornam-se imprescindiveis, em razão de a composição florística das plantas daninhas ser modificada por consequência das condições ecológicas, criadas artificialmente pelo homem nos agroecossistemas (Carvalho et al., 2008).

No manejo das plantas daninhas em sistemas orgânicos, o princípio da prevenção deve ser privilegiado, utilizando plantas com alta produção de palha e/ou com efeito alelopático, tendo capacidade de inibir o crescimento das plantas daninhas. Além dos efeitos químicos, oriundos da palha, outros efeitos físicos e biológicos, bem como a interação entre eles, contribuem para o controle das plantas daninhas (Vaz de Melo et al., 2007).

Considerando a limitação da grande maioria dos pequenos produtores em não utilizarem métodos de alta tecnologia, como a mecanização agrícola e produtos herbicidas, somados à escassez e ao alto custo da mão de obra, verifica-se que o manejo das plantas daninhas é um dos importantes fatores na produção de milho em sistema orgânico. Desse modo, a busca por alternativas para o manejo de plantas daninhas na cultura do milho orgânico torna-se essencial, visando à redução dos custos de produção e à busca pela manutenção do equilíbrio biológico. Assim, objetivou-se com este trabalho investigar as alterações na comunidade das plantas daninhas da cultura 
do milho-verde orgânico, em função de coberturas vegetais antecessoras de leguminosas em sistema de plantio direto.

\section{MATERIAL E MÉTODOS}

O ensaio foi instalado numa área que por 10 anos esteve sob cultivo, sem receber aplicações de agroquímicos industrializados.

Realizou-se o prévio plantio de leguminosas anuais herbáceas, semeadas em novembro de 2007, na Unidade de Produção Orgânica da Embrapa Milho e Sorgo, em Sete Lagoas-MG, localizada a $19^{\circ} 25^{\prime}$ de latitude sul e $44^{\circ} 15^{\prime}$ de longitude oeste e numa altitude de $732 \mathrm{~m}$. O clima é do tipo Aw (tropical estacional de savana), na classificação de Köppen. $\mathrm{O}$ ensaio foi conduzido em um Latossolo Vermelho distrófico típico, A moderado, fase cerrado subcaducifólio, relevo suave ondulado, e a análise química e textural apresentou os seguintes resultados: $\mathrm{pH}$ em água: 5,7 ; $\mathrm{P}$ e K: 11 e $108 \mathrm{mg} \mathrm{dm}^{-3}$, respectivamente; $\mathrm{Ca}, \mathrm{Mg}$ e $\mathrm{H}+\mathrm{Al}: 4,6,0,9$, e $4,0 \mathrm{cmol}_{\mathrm{c}} \mathrm{dm}^{-3}$, respectivamente; e 3,97 dag $\mathrm{kg}^{-1}$ de matéria orgânica, sendo classificado como muito argiloso por possuir 14,2 e $84 \%$ de areia, silte e argila, respectivamente.

Para o estudo das plantas daninhas, o experimento foi montado seguindo o delineamento em blocos ao acaso, com quatro repetições, em esquema de parcelas subdivididas, sendo a parcela constituída por diferentes palhadas para cobertura de solo, e a subparcela, por duas épocas de avaliação da população de plantas daninhas. Para as características relativas à produtividade de milho-verde adotou-se a mesma área, porém a coleta dos dados ocorreu na época da colheita. Os tratamentos constaram da avaliação de cinco espécies de leguminosas com potencial para adubação verde: feijão-de-porco (Canavalia ensiformes), guandu (Cajanus cajan), mucuna-preta (Mucuna aterrinum), mucuna-anã (Mucuna deeringiana), crotalária (Crotalaria juncea) e uma testemunha não capinada, na qual a vegetação cresceu livremente em pousio. Essas leguminosas foram semeadas no espaçamento de $50 \mathrm{~cm}$ entre fileiras, após inoculação com o rizóbio específico. A crotalaria foi cultivada num estande de 20 plantas $\mathrm{m}^{-2}$, e as demais leguminosas, em estandes de 10 plantas $\mathrm{m}^{-2}$.
Em fevereiro de 2008, as leguminosas foram roçadas rente ao solo. Nessa ocasião, foi avaliado o acúmulo de matéria fresca de cada espécie. Para isso, foi demarcada uma área de $1,0 \times 1,0 \mathrm{~m}$, onde se efetuou o corte, a pesagem do material e a amostragem para determinação do teor de água e nutrientes, visando ao posterior cálculo da produtividade de massa seca em $\mathrm{kg} \mathrm{ha}^{-1}$. Sobre essas palhadas, a cultura do milho foi semeada em março de 2008, por meio de semeadora de plantio direto. O tamanho das parcelas foi de $22,5 \mathrm{~m}^{2}$, constadas de cinco linhas de $5 \mathrm{~m}$, sendo o milho cultivado no espaçamento de $0,9 \mathrm{~m}$ entre linhas. Foram consideradas como área útil as três linhas centrais de milho $\left(10,8 \mathrm{~m}^{2}\right)$, descartando-se $0,5 \mathrm{~m}$ das suas extremidades. A população de plantas de milho foi estabelecida em 50.000 plantas ha ${ }^{-1}$, utilizando-se o cultivar HTMV 02, destinado à produção de milhoverde. $\mathrm{O}$ manejo fitossanitário da cultura foi realizado adotando-se práticas preconizadas pelas normas de produção orgânica (IBD, 2006). Não foi adicionada qualquer fonte de adubo mineral industrializado. Foram feitas irrigações semanais por aspersão em todas as parcelas, com lâmina de $20 \mathrm{~mm}$.

A amostragem da vegetação espontânea foi realizada aos 15 e 30 dias após a emergência (DAE) do milho, lançando-se de forma aleatória sobre cada unidade experimental um quadro de $50 \times 50 \mathrm{~cm}\left(0,25 \mathrm{~m}^{2}\right)$. As plantas daninhas dentro do quadro foram cortadas rente ao solo e separadas por espécie. Elas foram levadas ao laboratório, identificadas, contadas e pesadas, depois colocadas em estufa a $65^{\circ} \mathrm{C}$ até massa constante, para determinação da matéria seca.

A colheita das espigas verdes foi realizada no estádio de grãos leitosos. Foram determinadas a massa total de espigas verdes empalhadas e a massa de espigas verdes comerciais empalhadas, para avaliação da produtividade total de espigas com palha e produtividade de espigas comerciais com palha. Foram consideradas espigas empalhadas comerciais aquelas com tamanho superior a $22 \mathrm{~cm}$ e com aparência adequada à comercialização (ausência de manchas e de perfurações por pragas). Foram classificadas como espigas despalhadas comerciais aquelas com tamanho superior a $17 \mathrm{~cm}$ e com granação e sanidade 
adequada à comercialização (Silva et al., 2004). O comprimento de espigas comerciais com palha e sem palha e o diâmetro de espigas comerciais com palha e sem palha foram determinados com um paquímetro digital.

Para interpretação dos resultados, os dados obtidos foram submetidos à análise de variância; as diferenças significativas entre dados foram testadas pelo teste de Tukey, adotando-se nivel de significância de 5\%, utilizando-se o programa estatístico SAEG 9.0. Os dados para a variável número de plantas $\mathrm{m}^{-2}$ foram transformados em $(\mathrm{x}+1)^{1 / 2}$, para realização da análise estatística.

\section{RESULTADOS E DISCUSSÃO}

Não houve interação significativa entre espécies das leguminosas de cobertura e tempos de avaliação da ocorrência das plantas daninhas; assim, utilizaram-se as médias dos efeitos isolados dessas duas épocas (Tabela 1).

As espécies de plantas daninhas que ocorreram com maior densidade foram o capimcolchão (Digitaria ciliaris), picão-preto (Bidens pilosa), botão-de-ouro (Galinsoga ciliata), trapoeraba (Commelina benghalensis) e cordão-de-frade (Leonotis nepetaefolia). Com menores densidades registraram-se as populações de tiririca (Cyperus rotundus), poaiabranca (Richardia brasiliensis), timbete (Cenchurus echinatus), mentrasto (Ageratum conyzoides) e serralha (Sonchus oleraceus), que não apresentaram diferenças significativas entre os tratamentos. Verificou-se que as coberturas mortas com leguminosas reduziram a população das espécies de plantas daninhas em relação ao tratamento testemunha. As coberturas de crotalária reduziram a infestação de capim-colchão (Digitaria ciliaris), picão-preto (Bidens pilosa) e botão-de-ouro (Galinsoga ciliata). A leguminosa C. juncea proporcionou também eficiência na redução da germinação de Brachiaria decumbens e Pennisetum glaucum (Monquero et al., 2009). A leguminosa mucuna-preta inibiu a população de trapoeraba (Commelina benghalensis) e cordão-de-frade (Leonotis nepetaefolia), em relação à testemunha. No entanto, o feijão-de-porco reduziu o número de plantas $\mathrm{m}^{-2}$ do botão-de-ouro e picão-preto, e o guandu, apenas a população do botão-de-ouro.

Não foi observado nenhum efeito da cobertura de mucuna-anã sobre a população de plantas daninhas, uma vez que seu resultado foi similar ao observado na testemunha. A mucuna-anã, devido ao lento crescimento inicial e baixa produção de palhada, apresentou o pior resultado entre as leguminosas. A área em pousio, sob influência das plenas condições de luz, possibilitou o livre crescimento das plantas daninhas, tendo maior desenvolvimento, maior produção de sementes e maior produção de matéria seca.

Quanto à matéria seca das plantas daninhas, verificou-se que a maioria das espécies de leguminosas estudadas influenciou na produção da matéria seca destas (Tabela 2). Essa diminuição na produtividade de matéria seca das plantas daninhas na presença dessas

Tabela 1 - Número médio de plantas daninhas ocorridas sob diferentes palhadas de leguminosas. Sete Lagoas-MG, 2007/2008

\begin{tabular}{|l|c|c|c|c|c|}
\hline \multirow{2}{*}{ Cobertura } & Digitaria ciliaris & Bidens pilosa & Galinsoga ciliata & $\begin{array}{c}\text { Commelina } \\
\text { benghalensis }\end{array}$ & $\begin{array}{c}\text { Leonotis } \\
\text { nepetaefolia }\end{array}$ \\
\cline { 2 - 6 } & \multicolumn{5}{|c|}{$\left(\right.$ plantas $\left.\mathrm{m}^{-2}\right)$} \\
\hline Crotalária & $7,1 \mathrm{~b}$ & $4,9 \mathrm{~b}$ & $5,2 \mathrm{~b}$ & $5,2 \mathrm{bc}$ & $3,9 \mathrm{~b}$ \\
\hline Guandu & $16,1 \mathrm{ab}$ & $12,5 \mathrm{ab}$ & $6,1 \mathrm{~b}$ & $7,8 \mathrm{ab}$ & $4,1 \mathrm{ab}$ \\
\hline Feijão-de-porco & $15,8 \mathrm{ab}$ & $8,6 \mathrm{~b}$ & $7,7 \mathrm{~b}$ & $7,7 \mathrm{ab}$ & $4,1 \mathrm{ab}$ \\
\hline Mucuna-anã & $19,8 \mathrm{a}$ & $15,6 \mathrm{ab}$ & $9,1 \mathrm{ab}$ & $8,3 \mathrm{a}$ & $4,4 \mathrm{ab}$ \\
\hline Mucuna-preta & $15,0 \mathrm{ab}$ & $5,6 \mathrm{~b}$ & $6,0 \mathrm{~b}$ & $4,1 \mathrm{c}$ & $3,5 \mathrm{~b}$ \\
\hline Pousio & $20,0 \mathrm{a}$ & $25,9 \mathrm{a}$ & $14,7 \mathrm{a}$ & $8,5 \mathrm{a}$ & $6,8 \mathrm{a}$ \\
\hline CV $(\%)$ & 49,0 & 82,0 & 61,0 & 39,0 & 51,0 \\
\hline
\end{tabular}

Médias seguidas pela mesma letra na coluna não diferem estatisticamente pelo teste de Tukey a 5\% de probabilidade. Capim-colchão (Digitaria ciliaris), picão-preto (Bidens pilosa), botão-de-ouro (Galinsoga ciliata), trapoeraba (Commelina benghalensis) e cordão-defrade (Leonotis nepetaefolia). 
Tabela 2 - Produtividade de matéria seca das culturas de cobertura (MSC), número total de plantas daninhas (NTPD) e matéria seca das plantas daninhas (MSPD) coletadas aos 15 e 30 dias após a emergência (dae) da cultura do milho, em resposta à presença de diferentes coberturas com leguminosas sobre o solo. Sete Lagoas-MG, safra 2007/2008

\begin{tabular}{|l|c|c|c|c|c|}
\hline \multirow{2}{*}{ Cobertura } & \multirow{2}{*}{$\begin{array}{c}\text { MSC } \\
\left(\mathrm{kg} \mathrm{ha}^{-1}\right)\end{array}$} & NTPD 15 DAE & NTPD 30 DAE & MSPD 15 DAE & MSPD 30 DAE \\
\cline { 2 - 6 } & $9255,0 \mathrm{a}$ & $20,3 \mathrm{~b}$ & $48,8 \mathrm{~b}$ & $41,4 \mathrm{c}$ & $127,1 \mathrm{c}$ \\
\hline Crotalária & $4854,0 \mathrm{c}$ & $65,7 \mathrm{a}$ & $133,0 \mathrm{~b}$ & $62,8 \mathrm{~b}$ & $128,4 \mathrm{c}$ \\
\hline Guandu & $3154,0 \mathrm{c}$ & $50,7 \mathrm{ab}$ & $138,2 \mathrm{~b}$ & $56,5 \mathrm{~b}$ & $191,4 \mathrm{~b}$ \\
\hline Feijão-de-porco & $2992,0 \mathrm{~d}$ & $60,1 \mathrm{a}$ & $188,5 \mathrm{ab}$ & $73,0 \mathrm{a}$ & $197,1 \mathrm{~b}$ \\
\hline Mucuna-anã & $7520,0 \mathrm{~b}$ & $46,0 \mathrm{ab}$ & $106,5 \mathrm{~b}$ & $14,6 \mathrm{~d}$ & $95,2 \mathrm{~d}$ \\
\hline Mucuna-preta & $1513,0 \mathrm{e}$ & $67,7 \mathrm{a}$ & $361,2 \mathrm{a}$ & $84,7 \mathrm{a}$ & $224,6 \mathrm{a}$ \\
\hline Pousio & 16,0 & 35,4 & 37,1 & 12,0 & 14,0 \\
\hline CV $(\%)$ & & & \multicolumn{2}{|c|}{$\left(\mathrm{g}^{-2}\right)$} & \\
\hline
\end{tabular}

Médias seguidas pela mesma letra na coluna não diferem estatisticamente entre si pelo teste de Tukey a $5 \%$ de probabilidade.

coberturas deveu-se à interferência entre elas, ou seja, ao efeito físico, provocando abafamento, com redução da luminosidade, e, possivelmente, aos efeitos químicos ou alelopáticos provocados pelos lixiviados da palhada formada pelas leguminosas sobre as plantas daninhas.

Diminuição da população de plantas daninhas, proporcionada pelas espécies utilizadas em cobertura, foi relatada por Fernandez et al. (2008) e Aladesanwa \& Adigun (2008). Esses autores observaram ainda a interação entre densidade das plantas daninhas e nivel de resíduos vegetais no solo na cultura do milho, indicando supressão destas, em alguns tratamentos. Efeitos supressivos dos adubos verdes Arachis pintoi, C. juncea e C. cajan provocaram redução de populações das plantas daninhas Brachiaria decumbens, Panicum maximum e Bidens pilosa, auxiliando no manejo integrado, pois as infestações foram suprimidas pelos adubos verdes (Severino \& Christoffoleti, 2004).

A palhada de mucuna-preta possibilitou maior redução da matéria seca das plantas daninhas nas duas épocas, significando que esta leguminosa, em função de seu crescimento e desenvolvimento vigorosos, foi capaz de reduzir a população das plantas daninhas que ocorreram na área experimental. Embora não tenha sido a espécie que produziu maior quantidade de matéria seca por área (Tabela 2), foi a mais efetiva na redução da matéria seca das plantas daninhas, seguida pela crotalária. Conforme Favero et al. (2001), a mucuna-preta demonstrou maior potencial para cobertura do solo e supressão de plantas daninhas. Todavia, Blackshaw (2008) não relata efeito supressivo de sua palhada na cultura do feijoeiro comum. Analisando o efeito de leguminosas herbáceas anuais como cobertura de solo (mucuna-preta, feijãoguandu, feijão-de-porco e calopogônio), não se detectaram diferenças significativas para densidade, diversidade e matéria seca das plantas daninhas (Araújo et al., 2007). A diferença na cobertura do solo pelas leguminosas é atribuída a diversos fatores, dentre os quais destaca-se a própria arquitetura da planta e a velocidade com que cada espécie se desenvolve (Da Ros \& Aita, 1996). À medida que se aumenta a massa seca das leguminosas, diminui a matéria seca de plantas daninhas, ou seja, o acúmulo de matéria seca pelas coberturas é inversamente proporcional ao da matéria seca das plantas daninhas (Meschede et al., 2007).

O número total de matéria seca das plantas daninhas, na segunda época de avaliação, aumentou independentemente do tratamento (Tabela 2). O intervalo de tempo entre a primeira e a segunda avaliação possibilitou o desenvolvimento vegetativo das plantas que já estavam emergidas na primeira avaliação, ampliando o seu acúmulo de matéria seca, assim como a emergência de novas plântulas nesse intervalo de tempo. Na avaliação da interferência de oito espécies utilizadas como adubos verdes (Mucuna aterrima, Mucuna pruriens, Crotalaria ochroleuca, Crotalaria spectabilis, Canavalia ensiformis, 
Cajanus cajan, Pennisetum americanum e Sorghum bicolor, híbrido BR 304) sobre a comunidade infestante, verificou-se que C. spectabilis, S. bicolor, C. ochroleuca, $M$. aterrima e $M$. pruriens reduziram significativamente o número de plantas e o peso da matéria seca da população das plantas daninhas (D. horizontalis, $H$. lophanta e A. spinosus), principalmente as duas últimas (Erasmo et al., 2004).

Observou-se menor número total de plantas daninhas por metro quadrado aos $15 \mathrm{e}$ 30 DAE na palhada de crotalária, comparado aos demais tratamentos. De forma semelhante, a massa seca das plantas daninhas emergidas sob palhada de crotalária foi inferior à dos outros tratamentos, à exceção do tratamento com mucuna-preta. Dessa forma, a crotalária, além de produzir grande quantidade de matéria seca e assim possibilitar o aporte de nutrientes para a cultura em sucessão e também auxiliar no manejo de nematoides (Rosa et al., 2004), pode ainda, pelo efeito supressivo da vegetação espontânea, fazer parte do manejo cultural. A crotalária, durante seu cultivo no verão, cobriu rapidamente o solo e suprimiu o desenvolvimento das plantas daninhas, permitindo que no período crítico de competição com a cultura do milho estas plantas estivessem em populações inferiores às da área de pousio anterior. Quanto maior a quantidade de palha fornecida pela cultura, mais espessa é a cobertura morta formada e, portanto, maior é a influência sobre a germinação das sementes (Almeida, 1988).

No geral, quase todas as coberturas com leguminosas apresentaram valores de número total de plantas e matéria seca total das espécies daninhas inferiores aos do tratamento testemunha (pousio). Em outro trabalho, observaram-se reduções de $41 \%$ de infestação e de $74 \%$ de massa seca total de plantas daninhas, comparando-se os tratamentos cobertos com culturas à testemunha sem culturas, enquanto no segundo ano, aos 14 dias após a semeadura, não foram observadas diferenças entre a área onde havia plantas de sorgo ou milheto e a testemunha sem cobertura (Vidal \& Trezzi, 2004).

As coberturas de solo proporcionadas pelas leguminosas guandu e feijão-de-porco apresentaram desempenho intermediário na supressão de plantas daninhas e não conseguiram reduzir eficientemente a população dessas plantas, na cultura do milho-verde. Essas coberturas não diminuíram o número de plantas $\mathrm{m}^{-2}$, porém reduziram a matéria seca das plantas daninhas (Tabela 2). O feijão-de-porco, pelo fato de ter coberto o solo, possivelmente em função de efeito alelopático sobre as espécies daninhas, provocou redução da matéria seca das plantas daninhas e proporcionou boa produtividade do milho-verde (Tabela 3). Noutro experimento, verificou-se que a palhada da Gliricidia sepium foi benéfica ao milho e exerceu certo controle sobre as plantas daninhas (Silva et al., 2009).

Tabela 3 - Valores médios de comprimento de espigas comerciais com palha (CECP), comprimento de espigas comerciais sem palha (CECS), diâmetro de espigas comerciais com palha (DECP), diâmetro de espigas comerciais sem palha (DECS), produtividade total de espigas com palha (PTEP) e produtividade de espigas comerciais com palha (PECP) de milho-verde orgânico, em função das leguminosas de cobertura. Sete Lagoas-MG, safra 2007/2008

\begin{tabular}{|l|c|c|c|c|c|c|c|}
\hline \multirow{2}{*}{ Cobertura } & CECP & CECS & DECP & DECS & \multicolumn{2}{c|}{ PTEP } & \multicolumn{2}{c|}{$\left(\mathrm{kg} \mathrm{ha}^{-1}\right)$} \\
\cline { 2 - 8 } & \multicolumn{3}{|c|}{$(\mathrm{cm})$} & \multicolumn{2}{c|}{} \\
\hline Crotalária & 25,8 & 18,3 & 5,3 & 4,4 & $8788,0 \mathrm{a}$ & $6414,0 \mathrm{a}$ \\
\hline Guandu & 25,2 & 18,3 & 5,3 & 4,3 & $6540,0 \mathrm{~b}$ & $5448,0 \mathrm{~b}$ \\
\hline Feijão-de-porco & 26,1 & 18,7 & 5,4 & 4,3 & $8666,0 \mathrm{a}$ & $6136,0 \mathrm{~b}$ \\
\hline Mucuna-anã & 25,1 & 18,0 & 5,2 & 4,2 & $6466,0 \mathrm{~b}$ & $4992,0 \mathrm{c}$ \\
\hline Mucuna-preta & 25,8 & 18,7 & 5,4 & 4,3 & $9085,0 \mathrm{a}$ & $6644,0 \mathrm{a}$ \\
\hline Pousio & 25,0 & 18,0 & 5,2 & 4,2 & $6399,0 \mathrm{~b}$ & $4895,0 \mathrm{c}$ \\
\hline CV $(\%)$ & 4,4 & 4,3 & 3,1 & 3,0 & 17,3 & 15,5 \\
\hline
\end{tabular}

Médias seguidas pela mesma letra na coluna não diferem estatisticamente entre si pelo teste de Tukey a 5\% de probabilidade. 
O comprimento e o diâmetro das espigas com e sem palha não foram alterados pelas diferentes palhadas das leguminosas (Tabela 3). A produtividade, o comprimento e o diâmetro de espigas com ou sem palha foram satisfatórios se for levada em consideração a ausência da adição de insumos, como termofosfatos, estercos e compostos orgânicos (Tabela 3). Melhores produtividades podem ser obtidas utilizando-se insumos químicos (Vaz de Melo et al., 2007); entretanto, em sistema convencional, com uso de fertilizantes, observa-se produtividade semelhante à obtida no presente trabalho (Oliveira Jr. et al., 2006).

A maior produtividade total de espigas com palha foi obtida nos tratamentos sobre as coberturas de crotalária, feijão-de-porco e mucuna-preta (Tabela 3). A maior produtividade de espigas comerciais com palha de milho-verde orgânico foi obtida na cobertura de crotalária e mucuna-preta, possivelmente devido à maior matéria seca produzida por essas duas espécies, que proporcionaram maiores reduções da população de plantas daninhas e forneceram, pela sua mineralização, provavelmente, maior quantidade de nutrientes. Por sua vez, as produtividades observadas sob pousio e na palha de mucunaanã foram similares entre si e com indices menores no ensaio, provavelmente devido ao maior incremento da população de plantas daninhas.

Assim, a crotalária seguida da mucunapreta foram as espécies que mais produziram matéria seca. A mucuna-preta proporcionou a maior redução da massa seca das plantas daninhas, e a crotalária, a maior redução do número de plantas daninhas por área. As cinco espécies de plantas daninhas que mostraram diferenças significativas entre os tratamentos tiveram sua população reduzida pelas palhadas de crotalária e mucuna-preta. Sobre essas coberturas foram obtidas as melhores produtividades de espigas comerciais de milho-verde. Portanto, com os resultados obtidos, observase que, com o efeito da palhada, pode-se reduzir efetivamente o número e a matéria seca de plantas daninhas emergidas, permitindo à cultura do milho melhor desenvolvimento inicial devido à redução da interferência causada, estabelecendo condições para obter maior produtividade.

\section{AGRADECIMENTOS}

Ao CNPq, pela concessão da bolsa de estudo ao primeiro autor; à EMBRAPA, que financiou a pesquisa; e ao Departamento de Fitotecnia da Universidade Federal de Viçosa, pelo apoio científico aos experimentos.

\section{LITERATURA CITADA}

ALADESANWA, R. D.; ADIGUN, A. W. Evaluation of sweet potato (Ipomoea batatas) live mulch at different spacings for weed suppression and yield response of maize (Zea mays L.) in southwestern Nigeria. Crop Protec., v. 27, n. 6, p. 968-975, 2008.

ALMEIDA, F. S. A alelopatia e as plantas. Londrina: Fundação IAPAR, 1988. 60 p. (IAPAR Circular, 53).

ARAUJO, J. C. et al. Supressão de plantas daninhas por leguminosas anuais em sistema agroecológico na PréAmazônia. Planta Daninha, v. 25, n. 2, p. 267-275, 2007

BLACKSHAW, R. E. Agronomic merits of cereal cover crops in dry bean production systems in western Canada. Crop Protec., v. 27, n. 2, p. 208-214, 2008.

CARVALHO, L. B. et al. Interferência e estudo fitossociológico da comunidade infestante em beterraba de semeadura direta. Planta Daninha, v. 26, n. 2, p. 291-299, 2008.

CHIOVATO, M. G. et al. Diferentes densidades de plantas daninhas e métodos de controle nos componentes de produção do milho orgânico. Planta Daninha, v. 25, n. 2, p. 277-283, 2007.

CRUZ, J. C. et al. Importância da produção do milho orgânico para a agricultura familiar. In: CONGRESSO NACIONAL DE MLHO E SORGO, 26., 2006, Belo Horizonte.

Trabalhos apresentados. Sete Lagoas: ABMS/Embrapa Milho e Sorgo, 2006. CD ROM

DA ROS, C. O.; AITA, C. Efeito de espécies de inverno na cobertura do solo e fornecimento de nitrogênio ao milho em plantio direto. R. Bras. Ci. Solo, v. 20, n. 1, p. 135-140, 1996.

DAROLT, M. R.; SKORA NETO, F. Sistema de plantio direto em agricultura orgânica. R. Plantio Direto, v. 70, n. 1, p. $28-31,2002$

ERASMO, E. A. L. et al. Potencial de espécies utilizadas como adubo verde no manejo integrado de plantas daninhas. Planta Daninha, v. 22, n. 3, p. 337-342, 2004.

FAVERO, C. et al. Modificações na população de plantas espontâneas na presença de adubos verdes. Pesq. Agropec. Bras., v. 36, n. 11, p. 1355-1362, 2001

Planta Daninha, Viçosa-MG, v. 28, n. 2, p. 263-270, 2010 
FERNANDEZ, R. et al. A study of the effect of the interaction between site-specific conditions, residue cover and weed control on water storage during fallow. Agric. Water Manag., v. 95, n. 9, p. 1028-1040, 2008.

FONTANETTI, A. et al. Produção de milho orgânico no sistema de plantio direto. Inf. Agropec., v. 27, n. 233, p. 127-136, 2006.

INSTITUTO BIODINÂMICO - IBD. Diretrizes para orgânicos. Diretrizes IBD. 13.ed. Botucatu: 2009. 92 p. Disponível em: <http://www.ibd.com.br/diretrizes.htm> Acesso em: 6 fev. 2009

MESCHEDE, D. K.; FERREIRA, A. B.; RIBEIRO JR., C. C Avaliação de diferentes coberturas na supressão de plantas daninhas no cerrado. Planta Daninha, v. 25, n. 3, p. 465471, 2007.

MONQUERO, P. A. et al. Efeito de adubos verdes na supressão de espécies de plantas daninhas. Planta Daninha, v. 27, n. 1, p. 85-95, 2009.

OLIVEIRA JR., L. F. G. et al. Seleção de genótipos de milho mais promissores para o consumo in natura. Ci. Tecn. Aliment., v. 26, n. 1, p. 159-165, 2006.
ROSA, R. C. T.; MOURA, R. M.; PEDROSA, E. M. R. Efeitos do uso de Crotalaria juncea e carbofuran em fitonematóides ectoparasitos de cana-de-açúcar. Fitopatol. Bras., v. 29, n. 4, p. 447-449, 2004

SEVERINO, F. J.; CHRISTOFFOLETI, P. J. Weed supression by smother crops and selective herbicides. Sci. Agric., v. 61, n. 1, p. 21-26, 2004.

SILVA, J. et al. Efeito de esterco bovino sobre os rendimentos de espigas verdes e de grãos de milho. Hortic. Bras., v. 22, n. 2, p. 326-331, 2004.

SILVA, P. S. L. et al. Weed control via intercropping with gliricidia. II. Corn crop. Planta Daninha, v. 27, n. 1, p. 105-112, 2009.

VAZ DE MELO, A. et al. Dinâmica populacional de plantas daninhas em cultivo de milho-verde nos sistemas orgânico e tradicional. Planta Daninha, v. 25, n. 3, p. 521-527, 2007.

VIDAL, R. A.; TREZZI, M. M. Potencial da utilização de coberturas vegetais de sorgo e milheto na supressão de plantas daninhas em condição de campo: I - plantas em desenvolvimento vegetativo. Planta Daninha, v. 22, n. 2, p. 217-223, 2004. 